\title{
Tribromoisocyanuric Acid: a Benzylic Brominating Reagent
}

\author{
Leonardo Silva de Almeida, Marcio C.S. de Mattos, and Pierre M. Esteves \\ Departamento de Química Orgânica, Instituto de Química, Universidade Federal do Rio de Janeiro \\ leonardoalm@yahoo.com.br;mmattos@iq.ufr.br;pesteves@iq.ufr.br
}

Keywords: tribromoisocyanuric acid; bromination; arenes

\section{INTRODUCTION}

Benzylic bromination is a radical reaction which has attracted the interest of organic chemists and several methodologies are described in the literature for this important reaction. ${ }^{1}$

Tribromoisocyanuric acid (TBCA, Figure 1) is a stable solid, easily prepared by treatment of cyanuric acid with bromide and oxone. ${ }^{2}$ Some years ago, we introduced tribromisocyanuric acid as new and efficient reagent for electrophilic bromination reactions of unsaturated compounds.,<smiles>O=c1n(Br)c(=O)n(Br)c(=O)n1Br</smiles>

Figure 1. Tribromoisocyanuric acid (TBCA).

Continuing our interest on the chemistry of this fascinating reagent, we communicate here our initial results on the bromination reaction of organic compounds by TBCA in radical conditions.

\section{RESULTS AND DISCUSSION}

Ethylbenzene was chosen as model for testing the benzylic radical reaction with TBCA. The reaction was performed stirring together the substrate with 0.47 mol equiv of TBCA, catalytic amount of benzoylperoxide in EtOAc and irradiation with a 200 W lamp. After $3 \mathrm{~h}, \alpha$-bromoethylbenzene was isolated in $70 \%$ yield. However, the reaction performed in reflux EtOAc in the absence of the catalyst and without irradiation produced the same product in $84 \%$ isolated yield.

Based on the above results, we extended the reaction to toluene and fluorene, being the results shown in Table 1.

On the other hand, the reaction applied to cyclohexene led to a mixture of brominated compounds, as depicted in Figure 2.

\section{CONCLUSION}

We have described here an efficient benzylic radical reaction of TBCA. This new methodology has some attractive aspects, such as absence of catalyst and light and, specially, the utilization of EtOAc, instead of chlorinated solvents that are usually employed in such reactions. ${ }^{1}$

Table 1. Benzylic bromination reactions with TBCA.

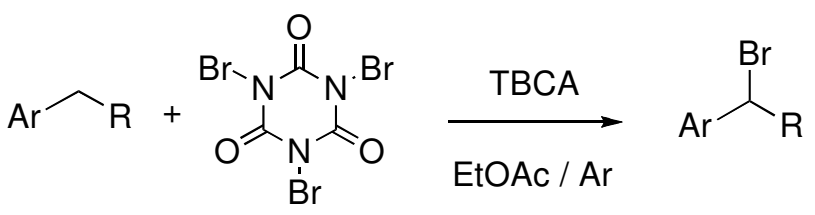

$\triangle$

\begin{tabular}{|l|l|l|}
\hline Arene & Time (h) & Yield (\%) \\
\hline
\end{tabular}

${ }^{\mathrm{b}}$ Formed along with $\alpha, \alpha$-dibromotoluene (8\%).

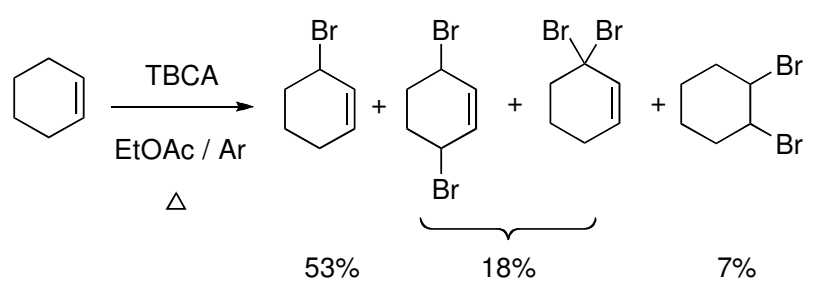

Figure 2. Radical reaction of cyclohexene with TBCA.

\section{ACKNOWLEDGEMENTS}

CNPq and FAPERJ

\section{REFERENCES}

${ }^{1}$ Ghorbani-Vaghei, R.; Chegini, M.; Veisi, H.; Karimi-Tabar, M. Tetrahedron Lett. 2009, 50, 1861.

${ }^{2}$ de Almeida, L.S.; Esteves, P.M.; de Mattos, M.C.S. Synlett 2006, 1515.

${ }^{3}$ de Almeida, L.S.; Esteves, P.M.; de Mattos, M.C.S. Tetrahedron Lett. 2009, 50, 3001.

${ }^{4}$ de Almeida, L.S.; Esteves, P.M.; de Mattos, M.C.S. Synthesis 2006, 221. 